\title{
The Forensic Analysis of Likelihood of Confusion among Brand Names: Case of Adidas and Abidas
}

\author{
Patrick Sadi Makangila (First \& corresponding author) \\ (MA, a Ph.D. candidate at the Central China Normal University) \\ E-mail: 3159632708@qq.com \\ Yesdauletova Sabira \\ (MA, a Ph.D. candidate at the Central China Normal University) \\ E-mail: sabira.askarovna@mail.ru
}

Received: March 24, 2020 Accepted: April 7, 2020 Published: April 8, 2020

doi:10.5296/jsel.v8i1.16813 URL: https://doi.org/10.5296/jsel.v8i1.16813

\begin{abstract}
This paper demonstrates how an expert in Forensic Linguistics, using his skills and abilities to come up with a legal decision-making based on scientific evidence in cases involving brand names under dispute. The very important aspect in the likelihood of confusion between two brand names is when two products have names which could make consumers a bit confused while the composition of both products has one or two different ingredients which could have some allergic reactions in the body of some consumers referring to sectors like the food industry, pharmaceutical sector and so on. The study states that the conflict on the trademarks Adidas and Abidas could be avoided if the linguists are called upon as experts while the junior brand looks for name about his new brand or in the courts for the legal decision-making between brands. For these reasons, the discussion tries to provide answers to the following research questions: (a) Can a forensic linguist provide relevant evidence in the conflicts between brand names? (b) What are aspects to take into consideration? (c) Is it possible to determine the likelihood of confusion between Adidas and Abidas? To answer these research questions, an authentic case was thoroughly examined. This involved revisiting the Community Trademark conflict between the earlier and international brand Adidas and Abidas. For purposes of analysis, the likelihood of confusion was taken into consideration in the review of the Adidas vs Abidas case.
\end{abstract}

Keywords: adidas, abidas, brand name, community trademark, linguist as an expert 


\section{Introduction}

In the business world, there are brand names which could bring confusion in the mind of consumers because of their similarities, and the most important thing is a junior brand could use this likelihood of confusion in their profits when a consumer does not have enough time to figure out that he is not buying the products that he was supposed to buy. In some cases, customers paid more for something that he could pay less as the price of senior brands' products are usually higher compared to the junior brands' products because of their high quality, high rate of demand and so forth.

Sometimes the inverse could happen and this is called reverse confusion which occurs when a junior user, generally through highly aggressive sales and marketing strategies and tactics, "hijacks" the senior user's brand and reputation to the point that consumers believe the goods of the senior user are those of the junior user. This is a direct reversal of the traditional forward confusion, in which consumers believe the junior user's products to be those of the senior user. With reverse confusion, the junior user so dominates the market as to overwhelm the senior user (Ameritech, 1987; quoted in James T. Berger \& R. Mark Halligan, 2012, p. $85)$.

\section{Aim of the Research}

This study aims to provide a solution in the trademark conflicts, by avoiding similarity in the brand names while designing and looking for how to name his brand.

\section{Literature Review}

Jacky Tai (2009) suggests ten rules to create a great brand name which are: name must be easy to pronounce, easy to remember, English-sounding, short, unique, no generic words, no acronym, you need two names, must have a dot.com suffix and the brand name must be language neutral.

What's in a name? When it comes to a brand, it means enormous value. The brand name is a fundamentally important choice of brand elements as it often captures the central theme or key associations of a product. Naming can be crucial to businesses. A good brand name can bring about unexpected advantages just like Apple, Pampers and Lux do, while a bad one can jeopardize the business just like Nova and Incubus do (Chuansheng H. \& X. Yunnan, 2006, p. $131)$.

Being a dream brand and distinctive among other competitors often results from the brand aspiration signals conveyed by the brand that the consumers choose to display and process ( $\mathrm{S}$. Sreejesh, 2015, p. 273).

Trademark and unfair competition law are concerned not only with confusion as to source, but also with confusion as to affiliation, connection, and sponsorship. Under the Lanham Act, the criteria for "confusion" are broad, and a federal claim for infringement of a non-registered 
trademark can result from a use that "is likely to cause confusion, or to cause mistake, or to deceive as the affiliation, connection or association" of the junior user with the senior user ( 15 U.S.C. ; quoted in James T. Berger \& R. Mark Halligan, 2012, p. 93).

James T. Berger \& R. Mark Halligan (2012, p. 96) notice that, under trademark law there are two distinct versions of "fair use," each of which permits the legal use of another's trademark. There is little similarity between the two versions. The first version is "classic fair use." Classic fair use occurs when the junior user is not using a descriptive, geographically descriptive, or personal name designation in a trademark sense, but only to describe the junior user's goods or services or geographic origin, or to name the person running the business. The second version is called "nominative fair use." Nominative fair use identifies the true trademark owner and generally involves "comparative advertising" campaigns (Cairns v. Franklin Mint Co. 2002; quoted in James T. Berger \& R. Mark Halligan, 2012, p. 96).

V. Guillén-Nieto (2011, p. 79-80) in her research on Respicort v. Respicur, she concludes that linguists as expert witness can provide relevant evidence in CTM disputes based on standard analytic linguistic method and tools, and illustrated the type of linguistic evidence that may be provided in cases involving CMT litigation, she adds that this may be of two main kinds, namely qualitative or quantitative data. Whereas the former involves the application of descriptive linguistics, the latter entails the use of descriptive statistics, and the results of this study proved that it is possible to determine and measure the strength of mark and the likelihood of confusion between two trademarks in dispute and she demonstrates how her study may hopefully contribute to a better understanding of the role of linguists as experts in CTM disputes and the way they can smooth the process of legal decision-making in such cases, and hence the linguistic analysis of brand names.

According to Hofmann, E. and S. Knébel (2016, p. 160) today, customers are becoming more and more sophisticated in terms of demand and are calling for individualized goods and services. At the same time, technological progress is shortening product life cycles and globalization is severing competition in most markets. This highly competitive, sophisticated and dynamic current economic environment is calling for innovative and adaptive business approaches.

Ethnic hatred, national culture, social effect can influence consumers whether to boycott, while consumers are consistent in behavior, but they are not based on the same motivation to make anti-brand behavior (Y. Yuan \& M. Lei, 2017, p. 143).

\section{The Case Study: Adidas v. Abidas}

In order to find out answers to questions raised in this research, we are going to scrutinize the Adidas and Abidas case.

\subsection{Preliminary study on the specific nature of sport brand names}

These two brand names Adidas and Abidas are both footwear brands, although they could dispose of some other accessories such as socks, sport clothes and so on, just like Puma, Nike, 
Umbro, and other sport brands.

\subsection{The classification of marks}

The two brands involved in the Community Trademark. Both Adidas and Abidas may be morphologically classified as a single word, normative, complex and descriptive especially Adidas this brand name. Adidas is pronounced as a single word although it comes from the association of two names put together"Adi”from Adolf and“das"from Dassler.

\subsection{Searching about the two Brands}

The background of Adidas one of the footwear brand giants in the world. Adolf was born on 3 November 1900. He was the founder and namesake for his company, Adidas which was a clever mixture of his nickname "Adi" and his last name "Dassler". The industrious Adi would be the first brother to make a big move towards the future. In the year 1920, he constructed a makeshift shoe production studio in a shed that his mother had previously used for laundry. Adi had only just returned from serving the German military in the First World War and was already looking towards building a future for himself at home. During the 1928 Olympic Games in Amsterdam, the Dassler brothers equipped German athlete Lina Radke with her running shoes. Radke went on to be the very first athlete to win an Olympic gold medal for Germany. This accomplishment would reflect well on the Dassler brothers and brought some notoriety to their burgeoning company (M. MacNabb, 2017, p. 16).

The test of "likelihood of confusion" is central to all trademark infringement and unfair competition disputes. Infringement of trademarks, service marks, and trade dress are all subject to a likelihood of confusion inquiry, which is the same for a service mark and a trademark (Lane, 1999; quoted in James T. Berger \& R. Mark Halligan, 2012, p. 85).

\subsection{Likelihood of confusion}

In this section, we are going to find out linguistic evidence to determine whether or not there is any likelihood of confusion between the marks Adidas and Abidas in terms of the two categories that are thought to be relevant from a legal standpoint, namely the category of sight (visual similarity) and the category of meaning (conceptual similarity).

\subsubsection{The category of sight (visual similarity)}

The category of sight involves all aspects of the visual appearance of a trademark, namely spelling, semiotic features such as color, typeface, and design, and linguistic principles of recognition and memory. These aspects were considered when examining the likelihood of confusion between Adidas and Abidas. The qualitative analysis was finally completed with the quantification of the graphemes shared between the senior mark and the junior mark. The brand names Adidas and Abidas were found to share five graphemes aligned in the same order:

A-d-i-d-a-s

A-b-i-d-a-s 

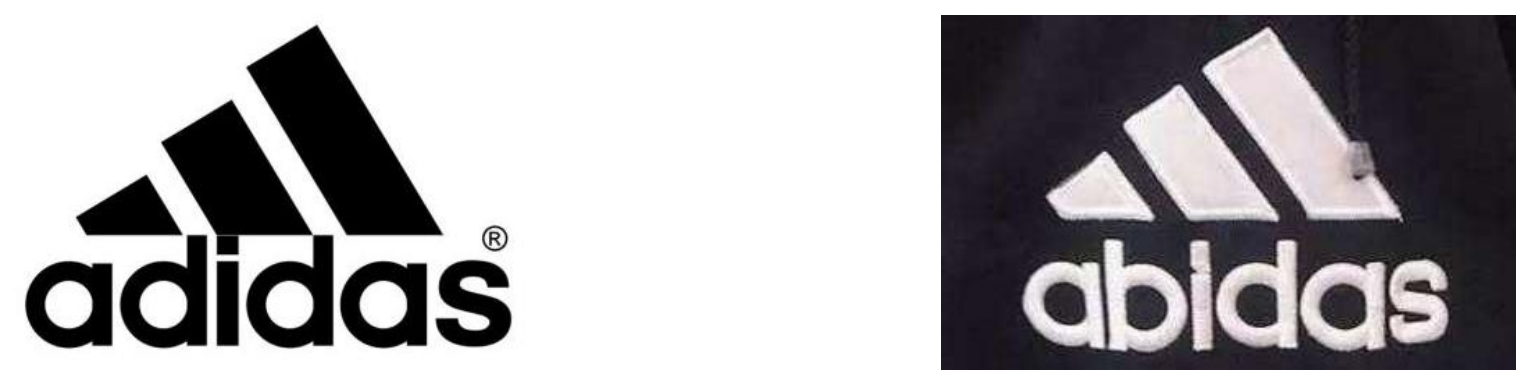

Grapheme 1 provides a visual illustration of the number of graphemes shared by Adidas and Abidas.

Graphemes shared by Adidas and Abidas (N)

\begin{tabular}{|l|l|l|l|l|l|}
\hline 6 & \multicolumn{2}{|l|}{} & Adidas & Abidas \\
\hline 5 & Adidas & Abidas & & Adidas & Abidas \\
\hline 4 & Adidas & Abidas & & Adidas & Abidas \\
\hline 3 & Adidas & Abidas & & Adidas & Abidas \\
\hline 2 & Adidas & Abidas & & Adidas & Abidas \\
\hline 1 & Adidas & Abidas & & Adidas & Abidas \\
\cline { 2 - 6 } & $\begin{array}{c}\text { Shared } \\
\text { graphemes }\end{array}$ & $5 / 5$ & & $6 / 6$ \\
\hline
\end{tabular}

Graphemes shared by Adidas and Abidas

Concerning linguistic principles of recognition and memory, it was observed that the customers who are supposed to be already familiarized with the earlier trademark Adidas, are likely to mistake Abidas for Adidas not only because the five letters in both marks are identical but also because the differences between them are minimal, namely "b" in "Abidas" the consonant quality of which is quite close to that of " $\mathrm{d}$ " in "Adidas". On reading the brand name Abidas, these six letters may create expectations in readers' minds and make them think, though rather unconsciously, that what they are reading is the already familiar brand name of the earlier German national trademark. In particular, Adidas and Abidas share five graphemes of the six graphemes found in Adidas and five graphemes of the six found in Abidas.

Thus $83 \%(10 / 12)$ are identical:

A-d-i-d-a-s $5 / 6$

A-b-i-d-a-s $\quad 5 / 6$

$10 / 12=83 \%$ 


\section{MInstitute Macrothink $_{\text {Ins }}$}

Drawing on the inductive probability scale recommended by the IAFL already referred to, the results of the morphological analysis showed a very high graphic similarity of $83 \%$ between Adidas and Abidas.

\subsubsection{The category of meaning (conceptual similarity)}

The meanings of these two brand names could have not a relationship with the exploitation sectors which is a sport. Brand name Adidas is a name made from two names, "Adi" and "das". "Adi" comes from "Adolf" and "das" from "Dassler", and Adi and Das put together to make Adidas, while the meaning of Abidas could be different from Adidas as they are two different brands. These two brands are sport equipment brands. Generally, sport brand names do not have specific prefixes or suffixes as it could be observed with some pharmaceutical brand names or pharmaceutical products such as Respicort and Respicur.

\section{Concluding Remarks}

In this study based on forensic analysis upon the two sport brand names Adidas and Abidas, looking for the likelihood of confusion, especially visual similarity, in order term the probability that consumer has to buy a product from a brand name A while he was expecting to buy from brand name B. This study answered the research questions and showed the importance of Linguist experts in such cases. The authors come with scientific evidence in which the category of sight which involves all aspects of the visual appearance of a trademark, namely spelling, semiotic features such as color, typeface, and design, and linguistic principles of recognition and memory, aspects which were considered while examining the likelihood of confusion between Adidas and Abidas are that the qualitative analysis was completed with the quantification of the graphemes shared between the senior mark Adidas and the junior mark Abidas as follow: the brand names Adidas and Abidas were found to share five graphemes aligned in the same order. From the inductive probability scale recommended by the IAFL already referred to, the results of the morphological analysis showed a very high graphic similarity of $83 \%$ between Adidas and Abidas.

\section{Further Research and Outlook}

This research recognizes the importance of associating Linguist experts in the Community Trade Mark conflicts for better analysis to come up with a conclusion based upon scientific evidence and a multidisciplinary approach could be a plus. The authors further recommend more aspects to take into consideration in the case of brand names conflicts such as the category of sound or sound similarity and also a survey to the consumers, sellers, athletes, responsible of sport organizations and so forth to have as much as possible scientific evidence because, in case of a dispute between two brand names, there are many factors which must be considered, at the extend the experts will need to see when the two brands were registered in the country where the so-called junior brand could be accused to justice for violating trademark policies. 


\section{Acknowledgement}

The authors wish to thank Professor Dr. Victoria Guillen-Nieto who is a Senior Lecturer in Applied Linguistics in the Department of English Studies Faculty of Humanity and Arts Campus de San Vicente del Raspeig, University of Alicante for her series of lectures in Forensic Linguistics in 2017 at Central China Normal University where we learned deeply about Community trademark (CTM) dispute, plagiarism, and so forth. Furthermore, special thanks go to the reviewers of this paper for their useful and motivating comments.

\section{References}

Chuansheng, H., \&Yunnan, X. (2006). Brand Name Translation in China: An Overview of Practice and Theory. Fédération des Traducteurs (FIT) Revue Babel, 49(2), 131-148.

Guillén-Nieto, V. (2011). The Linguist as Expert Witness in the Community Trademark. International Journal of Applied Linguistics, 162, 63-83. http://dx.doi.org/10.1075/itl.162.04gui

Hofmann, E., \& Knébel, S. (2016). Supply Chain Differentiation: Background, Concept and Examples. Journal of Service Science and Management, 9, 160-174. http://dx.doi.org/10.4236/jssm.2016.92020

MacNabb, M. (2017). A Secret History of Brands: The Dark and Twisted Beginnings of the Brand Names We Know and Love. South Yorkshire/England: Pen and Sword.

Sreejesh, S. (2015). Consumers' Perceived Brand Aspiration and Its Impact on Intention to Pay Price Premium: Moderating Role of Brand Jealousy. Theoretical Economics Letters. 5, 273-284. http://dx.doi.org/10.4236/tel.2015.52033

Tai, J. (2009). Get a Name! 10 Rules to Create a Great Brand Name. Singapore: Marshall Cavendish Business.

Yuan, Y., \& Lei, M. (2017). The Negative Effect of Brand Attachment: How Attachment Styles Help Explain Anti-Brand Behavior. Open Journal of Business and Management, 5, 141-148. http://dx.doi.org/10.4236/ojbm.2017.51013 
Biographical Notes 2020, Vol. 8, No. 1

Patrick Sadi Makangila is a Ph.D. candidate at Central China Normal University taking up a major in English Language and Literature, specializing in Translation. He graduated from the University of Kinshasa and earned his master degree in Translation and Interpreting from Central China Normal University, China in 2017. He has published one literary book in Chinese, and already published four research papers in Applied Linguistics, Literature and Translation.

Yesdauletova Sabira is a Ph.D. candidate at Central China Normal University taking up a major in Foreign and Applied Linguistics. She graduated from Kazakh National Pedagogical University named after Abai, earned her MA degree in pedagogical science in 2015.

\section{Copyright Disclaimer}

Copyright for this article is retained by the author(s), with first publication rights granted to the journal.

This is an open-access article distributed under the terms and conditions of the Creative Commons Attribution license (http://creativecommons.org/licenses/by/3.0/). 